\title{
SOBRE A LINGUAGEM MATEMÁTICA NA FORMAÇÃO INICIAL DE PROFESSORES
}

\author{
ON MATHEMATICAL LANGUAGE IN INITIAL TEACHER TRAINING
}

\author{
Francisco Wagner Soares Oliveira ${ }^{1}$
}

\begin{abstract}
RESUMO
Neste artigo, são revisitados os dados de uma pesquisa que buscou construir interfaces entre história e o ensino de matemática na formação inicial de professores, a partir do processo de construção e uso do instrumento jacente no plano. Aqui, os olhares estão voltados a Linguagem Matemática dos discentes, faladas ou escritas na ação, ou seja, durante o desenvolvimento da atividade. Em particular, tem-se como objetivo identificar a precisão na Linguagem Geométrica de licenciandos em matemática. Para tanto, fez-se o estudo à luz de uma pesquisa bibliográfica e também de uma qualitativa documental. Como se pode observar na atividade, por exemplo, que os discentes se referem ao arco de uma circunferência como sendo uma reta, onde, na verdade ele é um segmento de reta; falam também sobre a construção de um plano por meio de um barbante (reta), entretanto para se ter um plano são necessárias no mínimo duas retas; mencionam ainda que duas retas perpendiculares não são planas, porém, sabe-se que duas retas perpendiculares formam um plano, visto que são concorrentes. Nesses termos, os dados apontam que existe uma imprecisão na Linguagem Geométrica dos discentes em formação inicial. Diante desse fato, entende-se que é necessário que docentes de curso de Licenciatura em Matemática façam intervenções e discutam com os discentes possíveis equívocos na linguagem. A fala dos estudantes dá indícios do movimento do pensamento que eles fazem para atribuir significado a objetos conceituais, assim ela pode ser tomada pelos docentes como ferramenta para conduzir os discentes a uma aprendizagem ampla e sólida.
\end{abstract}

Palavras-chave: Linguagem Geométrica; formação inicial de professores de matemática; interface entre história e ensino de matemática.

\begin{abstract}
This article revisits the data of a research that sought to build interfaces between history and the teaching of mathematics in the initial training of teachers, based on the process of construction and use of the "instrumento jacente no plano". Here, the looks are focused on the mathematical language of students spoken or written in action, that is, during the development of the activity. In particular, it aims to identify the precision in the geometric language of undergraduate mathematics students. To this end, the study was carried out in the light of a bibliographic research and also a qualitative document. As it can be seen in the activity, for example, that students refer to the arc of a circumference as being a line, where in fact it is a line segment; they also talk about building a plane by means of a string (straight line), however to have a plane, at least two lines are necessary; they also mention that two perpendicular lines are not flat, however, it is known
\end{abstract}

\footnotetext{
${ }^{1}$ Mestre em ensino de ciências e matemática pelo Instituto Federal de Educação Ciências e Tecnologia do Ceará (IFCE). Doutorando da PPGE Universidade Estadual do Ceará (UECE), Fortaleza, Ceará, Brasil. Endereço para correspondência: Rua Nossa Senhora de Fátima, 124, Bandeira Velho, Itatira, Ceará, Brasil, CEP: 62720-000. E-mail: wagner.oliveira@aluno.uece.br.

D ORCID iD: http://orcid.org/0000-0001-9296-8200.
} 
that two perpendicular lines form a plane, since they are concurrent. In these terms, the data indicate that there is an imprecision in the geometric language of students in initial training. In view of this fact, it is understood that it is necessary for teachers of the Mathematics Degree course to make interventions and discuss possible mistakes in the language with the students. The students' speech gives evidence of the movement of thought they make to assign meaning to conceptual objects, so it can be taken by teachers as a tool to lead students to broad and solid learning.

Keywords: Geometric Language; initial training of mathematics teachers; Interface between history and mathematics teaching. 


\section{Introdução}

Nesse estudo, o objetivo é identificar a precisão na Linguagem Geométrica de licenciandos em matemática. Nessa direção, para a análise, foram revisitados os dados da atividade desenvolvida na pesquisa de Oliveira (2019). Nela, o autor trabalha conhecimentos geométricos incorporados na obra De arte atque ratione navigandi $(2008)^{2}$, em particular, a partir da descrição de construção e uso do instrumento jacente no plano ${ }^{3}$ proposto por Pedro Nunes ${ }^{4}$ (1502-1578). Aqui são tomados como objetos de análise tanto as falas captadas por gravações de vídeo e áudio como também os registros escritos pelos sujeitos em fichas de atividades e relatórios.

Diante desses métodos de coleta dos dados utilizados por Oliveira (2019), o presente artigo foi realizado com base em uma pesquisa bibliográfica e em outra de natureza qualitativa documental. O estudo bibliográfico, entra em cena, por ter como finalidade "[...] colocar o pesquisador em contato direto com tudo o que foi escrito, dito ou filmado sobre determinado assunto, inclusive conferências seguidas de debates que tenham sido transcritos por alguma forma, quer publicadas, quer gravadas" (MARCONI; LAKATOS, 2003, p. 183). Sob esse aporte, buscou-se observar o que a literatura acadêmica tem falado sobre a Linguagem Matemática.

A pesquisa documental, se trata de um "[...] exame de materiais de natureza diversa, que ainda não receberam um tratamento analítico, ou que podem ser reexaminados, buscando-se novas e/ ou interpretações complementares" (GODOY, 1995, p. 21). Nesse sentido, ela é aqui tomada como método para revisitar e analisar os dados coletados na atividade em questão.

$\mathrm{Na}$ sequência da exposição desse estudo, tem-se na próxima seção algumas informações relativas à atividade de construção e uso do instrumento jacente no plano. Posteriormente, expõe-se o referencial teórico que trata sobre Linguagem Matemática e que é tomado como referência para revisitar os dados da ação formativa. Na penúltima seção, tem-se a análise e discussão dos dados. Por fim, são apresentadas as notas finais.

\footnotetext{
${ }^{2}$ De arte atque ratione navigandi, de 2008, trata-se de uma obra de navegação que aborda a arte e a ciência de navegar. Para maiores detalhes, consulte: Almeida (2011), Leitão (2006, 2008) e Oliveira (2019).

${ }^{3}$ Sua função é determinar a altura do Sol acima do horizonte. Para detalhes, ver Almeida (2011), Canas (2011), Leitão (2008), Nunes (2012), Oliveira e Pereira (2019), Reis (2003), Albuquerque (1988) e Oliveira (2019).

${ }^{4}$ Sobre Pedro Nunes, ver Leitão (2003).
} 


\section{Alguns elementos da atividade revisitada}

A atividade formativa aqui revisitada, foi intitulada por "mobilizando conhecimentos geométricos a partir da construção e uso do instrumento português jacente no plano (1566)". Ela se trata da terceira etapa da pesquisa, de mestrado, de Oliveira (2019) e faz parte de uma das ações do Projeto Guarda-chuva, o qual está associado ao Programa de Formação Docente (PFD). ${ }^{6} \mathrm{O}$ foco nesse programa está em construir interfaces entre história e ensino de matemática a partir do estudo de instrumentos matemáticos históricos, com base em uma perspectiva historiográfica atualizada.

$\mathrm{Na}$ interface em questão, o objetivo geral do estudo foi conhecer o potencial didático do instrumento jacente no plano para o ensino de conhecimentos geométricos na formação inicial de professores. Atrelado a essa intenção, a atividade foi desenvolvida no ano de 2019, nos dias de 01 a 03 de agosto, com carga horária de 20h aulas no formato de um curso de extensão e, teve como público 12 discentes da Licenciatura em Matemática da Universidade Estadual do Ceará - UECE, os quais foram distribuídos em 4 grupos. A ação ocorreu nas dependências da UECE, especificamente no Laboratório de Matemática e Ensino Professor Bernardo Rodrigues Torres (LAbMAtEn/UECE).

Os pressupostos teóricos e metodológicos da ação formativa foram baseados na Atividade Orientadora de Ensino - AOE (MOURA et al. 2016). Na primeira etapa da formação, os discentes tiveram que estudar o instrumento jacente no plano à luz da descrição de construção apresentada por Nunes (2008), na segunda etapa foi incorporado no estudo elementos do uso do aparato e uma réplica física do instrumento, já na terceira etapa, o foco foi o estudo do uso do instrumento jacente no plano a partir de uma situação prática de uso. $^{7}$

\section{A Linguagem Matemática e Educação Matemática}

A área de Educação Matemática, a qual busca tratar de questões relacionadas ao processo de ensino e aprendizagem de matemática, abre espaço para professores e pesquisadores discutirem questões relacionadas a Linguagem Matemática apresentada em

\footnotetext{
${ }^{5}$ Este curso se desenvolveu após passar pelos tramites legais na Plataforma Brasil e está amparado no parecer favorável do conselho de ética sob número 3.553.179.

${ }^{6}$ O Projeto Guarda-chuva está associado à Pró-reitoria de Extensão da Universidade Estadual do Ceará (UECE) e contempla estudos do Grupo de Pesquisa em Educação e História da Matemática (GPEHM) da UECE.

${ }^{7}$ Para detalhes sobre a atividade de construção e uso do instrumento jacente no plano ver Oliveira (2019).
} 
sala de aula, seja por professores ou por estudantes. ${ }^{8}$ Sabe-se que a linguagem pode ser expressa no ambiente escolar tanto de forma oral como também escrita. ${ }^{9}$

Uma justificativa para se considerar a linguagem no processo de ensino e aprendizagem de matemática, repousa no fato de se entender que ela tem "[...] efeito formativo importante na compreensão da matemática por parte dos alunos. De acordo com Gawned (1990), cada sala de aula de matemática tem uma cultura particular própria" (ELLERTON; CLARKSON, 1996, p. 990, tradução nossa) ${ }^{10}$.

Nesses termos, Ellerton e Clarkson (1996) apontam que a linguagem tem influência na aprendizagem dos estudantes, e que ela é permeada pelo contexto ao qual os sujeitos fazem parte. Gawned (1990) em seus estudos já apontava para esse fato, vide (figura 1):

Figura 1 - Um resumo do 'modelo' sócio-psico-linguístico de Gawned (1990)

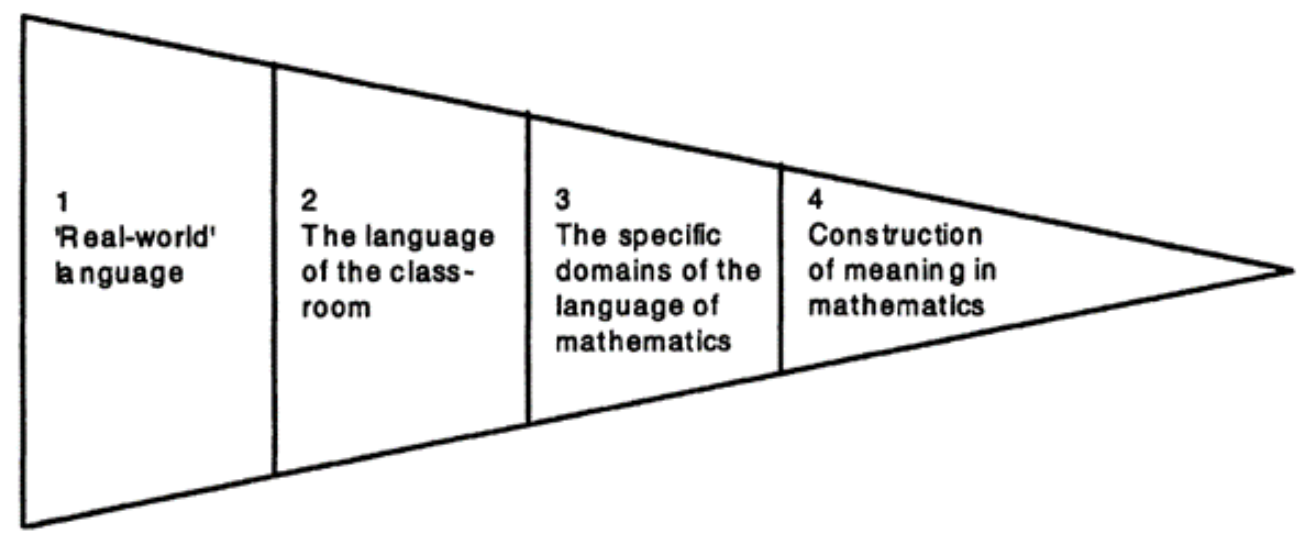

Fonte: Gawned (1990, apud ELLERTON; CLARKSON, 1996, p. 990)

O primeiro item, que está na base desse triângulo, refere-se à língua do mundo real, já o segundo, está atrelado ao idioma na sala de aula, por sua vez, o terceiro trata dos domínios específicos da Linguagem Matemática e, por fim, o quarto, representa a construção de significados em matemática. Essa estrutura, que vai afunilando para a construção de significados ilustra o caráter formativo que a linguagem pode exercer, visto

\footnotetext{
${ }^{8}$ Ellerton e Clarkson (1996), trazem um breve contexto histórico de iniciativas que discutem fatores de linguagem no trabalho com a matemática.

${ }^{9}$ No caso da linguagem no âmbito da matemática, Usiskin (1996), ainda sinaliza a linguagem como uma expressão pictórica, a qual se refere ao trabalho com gráficos, diagramas, desenhos, dentre outros recursos nesse sentido.

10 important formative effect on learners' understandings ofmathematics. According to Gawned (1990), each mathematics classroom has a particular culture of its own.
} 
que ela se constitui a partir das experiências dos sujeitos vivenciadas desde o primeiro contato com o mundo real.

Tomando como referência a linguagem no processo de formação do pensamento da criança, sabe-se que:

\begin{abstract}
A maneira como as pessoas comunicam-se com as crianças, especialmente a linguagem que usam, ajudam na organização das próprias percepções da criança [...] A linguagem ajuda a moldar essas experiências internas (mentais) e experiências externas. Eles recebem nomes e descrições. O uso deles começa a se encaixar em um padrão previsível. As crianças desenvolvem esquemas para o dia a dia ou outros eventos regulares nos quais o novo idioma é então mapeado. Simultaneamente, as próprias percepções e experiências da criança servem como um estímulo para ele (sic.) iniciar interação e se comunicar com aqueles ao seu redor (GAWNED, 1990, p. 31, tradução nossa).
\end{abstract}

Nesse sentido, Gawned (1990) reforça a ideia da linguagem como uma ferramenta capaz de influenciar a compreensão e aprendizagem dos sujeitos, visto que ela é responsável por desencadear reflexões e processos de pensamento. Da tentativa de definila, cabe destacar que:

\begin{abstract}
A linguagem, em sentido lato, corresponde a um "meio de comunicação utilizado por uma comunidade (...) para transmitir mensagens. Em sentido mais estrito, a linguagem é vista como um sistema de signos directos ou naturais e pressupõe um sujeito falante e implica fenómenos ligados à transmissão da mensagem dentro de um contexto espacial-temporal e cultural chamado situação. $\mathrm{O}$ estudo da linguagem comporta, pois aspectos psicológicos (os psicólogos falam de actividade da linguagem), sociológicos, etnológicos e mesmo psicanalíticos (MENEZES, 2000, p. 3).
\end{abstract}

Trazendo para a sala de aula de matemática, notam-se essas duas facetas da linguagem, tanto no sentido lato como também estrito. No caso do ensino e aprendizagem de conceitos matemáticos, pode-se observar em grande medida, uma linguagem formal própria (estrito), “[...] em que a linguagem, além de ter que se submeter às regras da sintaxe, preestabelecidas, deve satisfazer a condições mínimas de organização linear, gradativa” (MACHADO, 2013, p. 96). Ao tratar especificamente da matemática, “[...] estamos perante um meio de comunicação possuidor de um código próprio, com uma gramática e que é utilizado por uma certa comunidade” (MENEZES, 2000, p. 4).

Ou seja, é necessário respeitar símbolos, conectivos e estruturas próprias da área de matemática, somente, assim consegue-se dentro de um contexto formal expressar as ideias matemáticas de maneira mais inteligível para um grupo. Sem esse cuidado, “[...] 
mesmo as boas ideias, quando expressas de forma incompreensível, perdem seu valor" (MORAIS FILHO, 2010, p. 5).

Deve-se ter em conta ainda, que "a linguagem da matemática é híbrida, pois resulta do cruzamento da linguagem da matemática com uma linguagem natural, no nosso caso, o português" (MENEZES, 2000, p. 5). Dessa forma, é imprescindível que pesquisadores, professores e estudantes busquem conciliar essas linguagens, ao se expressarem, sem renunciar a lógica e rigor do conhecimento matemático.

No caso da linguagem escrita, é consenso que:

Quando se escreve, melhora-se a convicção nos próprios argumentos, apurase o raciocínio, e é quando podem surgir novas ideias. Escrever é uma maneira de pensar, de organizar o que se deseja comunicar. Ao escrever, não é incomum surgirem ideias inesperadas. Outras vezes, é quando se redige que descobrimos erros nos raciocínios que jurávamos estar corretos (MORAIS FILHO, 2010, p. 5-6).

Essas palavras, reforçam mais uma vez, a compreensão de que a linguagem é uma ferramenta formativa, assim como destacam Ellerton e Clarkson (1996). Nesses termos destacados por Morais Filho (2010), a escrita possibilita o desencadeamento de reflexões que ocorrem no pensamento sobre determinados objetos conceituais. Nesse sentido o simples ato de escrever favorece o desenvolvimento do movimento do pensamento do sujeito. ${ }^{11}$

Na próxima seção, observa-se a Linguagem Matemática apresentada por discentes do curso de Licenciatura em Matemática. Os olhares estão voltados aos diálogos e as escritas realizadas no curso de formação destacado na seção anterior, eles são revisitados como objetos de análise visto terem incorporado indícios do movimento do pensamento realizado pelos sujeitos.

\section{Revisitando os dados da interface entre história e ensino de matemática}

As falas dos estudantes em formação inicial emergem durante todos os momentos da ação formativa. Sobre elas, busca-se pontuar algumas das colocações apresentadas de forma escrita e oral. Inicialmente, o foco está voltado a etapa em que tentaram entender

${ }^{11} \mathrm{Na}$ proposta de interface entre história e ensino de matemática assumida na pesquisa, que aqui é revisitada, Oliveira (2019), o movimento do pensamento é visto como o movimento que o aluno faz no pensamento para apreender o objeto (SAITO; DIAS, 2013). 
elementos do processo de construção do aparato; na sequência é dado destaque ao momento de uso do instrumento jacente no plano, no qual os discentes tiveram que determinar a altura do Sol acima do horizonte; para finalizar, são revisitados trechos do momento que tiveram que discutir as estratégias utilizadas na situação prática.

Ao tentar compreender o processo de construção do instrumento jacente no plano, o Aluno 4 faz uma crítica matemática a um dos excertos descritos por Nunes (2008). Especificamente, quando o autor afirma que "se se duplicarem os lados do triângulo fgh, de maneira a que o lado gh seja igual ao diâmetro ac e se ajuste perfeitamente a ele, poderse-á dividir o semicírculo abc em noventa partes iguais e então os graus da altura do Sol serão duplamente maiores (NUNES, 2008, p. 359, grifo nosso). Na concepção inicial do Aluno 4, está incoerente porque (figura 2):

Figura 2 - Crítica do aluno sobre a instrução de que "se se duplicarem os lados do triângulo fgh"

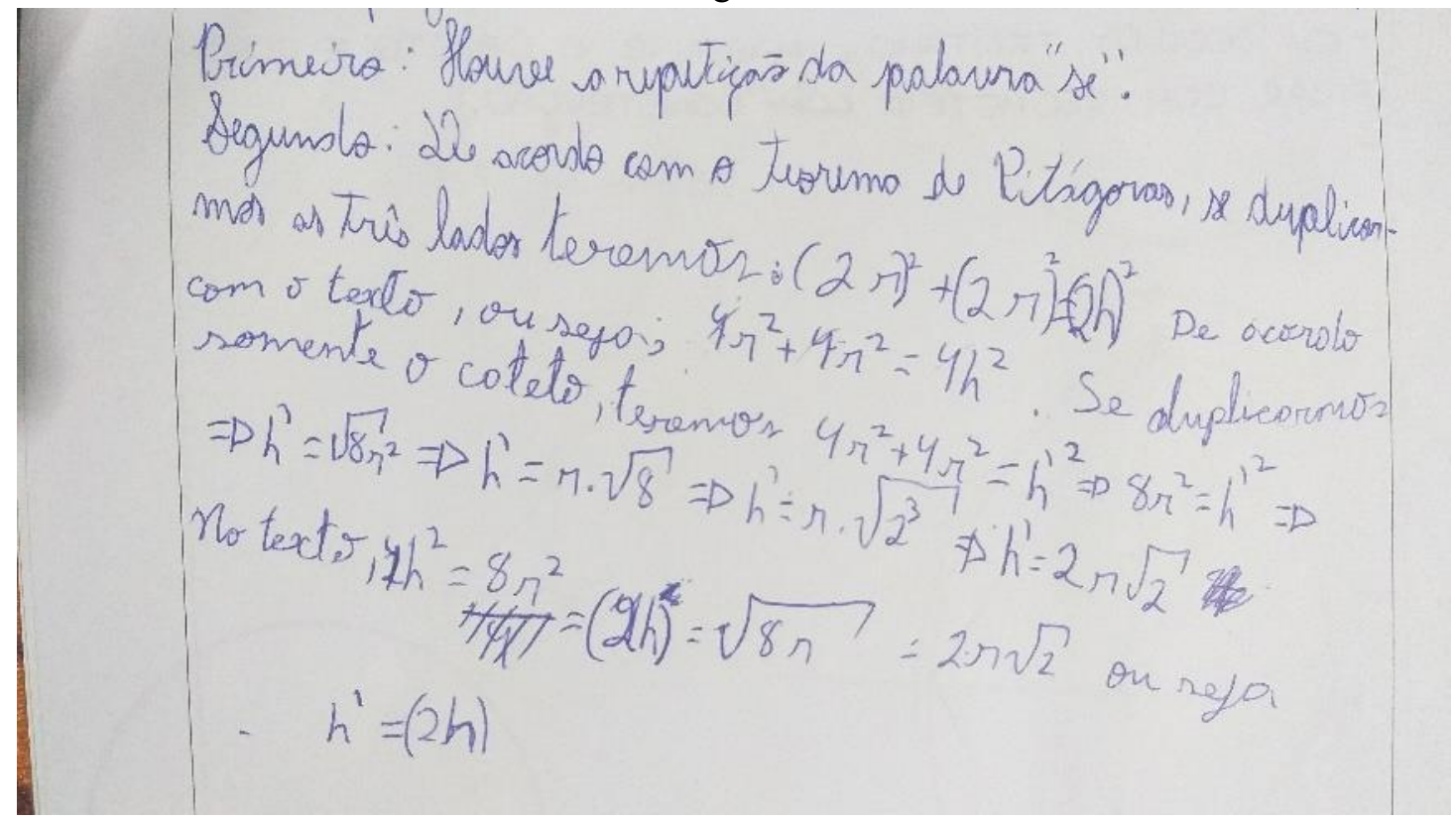

Fonte: Oliveira (2019)

Se contrapondo a crítica desse discente, outro aluno pontua que, por exemplo, "o triângulo 3, 4 e 5 que é um triângulo retângulo, os múltiplos também funcionam" (ALUNO 11, 2019). Diante desse impasse entre os argumentos dos participantes, eles foram questionados: “duplicar significa o que?". Um deles responde que "multiplicar por dois, vai ser um múltiplo do triângulo" (ALUNO 11, 2019) e outro complementa: "não seria lados proporcionais, não?" (ALUNO 3, 2019). Ao final da discussão sobre a 
impossibilidade de duplicação levantada, chegam à conclusão de que ela é possível, quem discordava destacou que: “[...] não estava certo, eu pensei em espelhar em $2 \sqrt{ } 2$, só que $\sqrt{ } 2$ já está inserido no primeiro triângulo" (ALUNO 4, 2019).

Conforme descrito na figura 2, nota-se que o Aluno 4 teve problemas no uso do teorema de Pitágoras, como forma de sustentar sua crítica. Visto que, pelo contrário, com base nesse teorema, pode-se ver que realmente a duplicação é possível. Para o triângulo sem lados duplicados, tem-se $h^{2}=r^{2}+r^{2}$, o que implica que $h=r \sqrt{ } 2$, o mesmo é válido para o triângulo com lados duplicados, pois $(2 \mathrm{~h})^{2}=(2 \mathrm{r})^{2}+(2 \mathrm{r})^{2}$ implica em $\mathrm{h}=\mathrm{r} \sqrt{ } 2$.

Diante dessa discussão desencadeada a partir da fala de um dos alunos, nota-se como apontam Ellerton e Clarkson (1996), que de fato a linguagem pode ser tomada como um elemento para favorecer a formação. À luz da concepção de Morais Filho (2010), nota-se que a partir de um diálogo e de uma nova interpretação de sua escrita, o Aluno 4 pôde refletir e observar que tinha pensado inicialmente de forma equivocada.

Ainda em relação a interpretação do texto de Nunes (2008), em especial a incorporação do estilete ${ }^{12}$, o grupo 1 , fez a seguinte colocação (figura 3 ):

Figura 3 - Escrita do Grupo 1 sobre o trabalho com o estilete

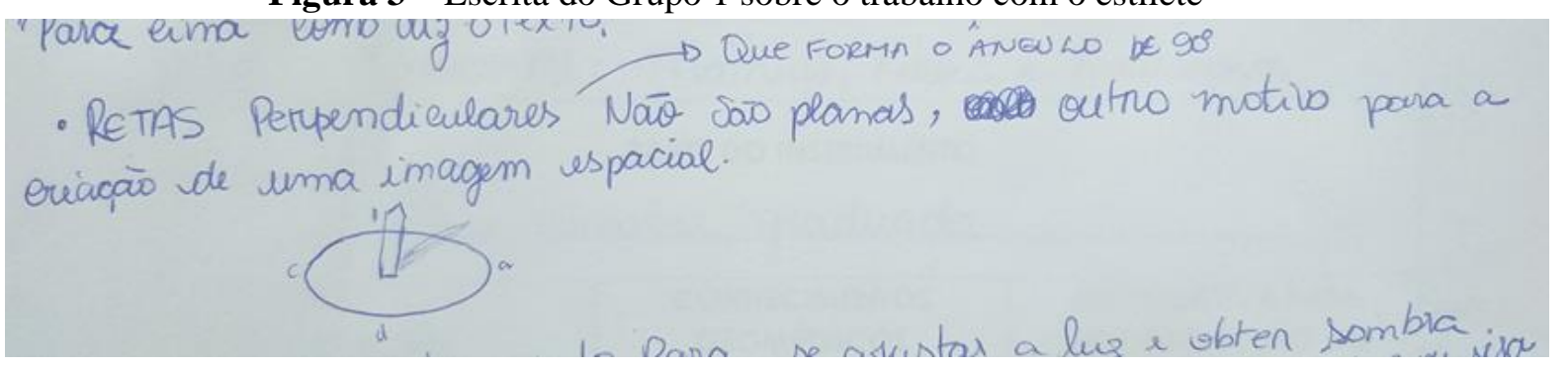

Fonte: Oliveira (2019)

Nesse trecho "retas perpendiculares que forma o ângulo de $90^{\circ}$ não são planas", nota-se uma certa imprecisão na Linguagem Geométrica. De acordo com a sistematização geométrica aceita e praticada entre matemáticos, duas retas perpendiculares formam um plano, visto que elas "têm exatamente um ponto em comum, [...] e sempre determinam um plano" (LIMA, et al. 2016, p. 156).

12 O estilete é uma das partes do instrumento jacente no plano para a sua versão na tábua circular, confira Nunes (2008) e Oliveira (2019). 
Em outro momento, ao discutirem a fabricação de uma das partes do instrumento jacente no plano, o triângulo retângulo isósceles, o Aluno 4 apresenta a seguinte fala, que segue ao mesmo tempo o desenho de construção:

\begin{abstract}
"Eu pego uma reta qualquer, coloco dois pontos, esses pontos serão meus centros, vou pegar o raio da minha tábua, no caso deixei em escala maior porque eu criei uma tábua pequena, que é só mesmo um exemplo. Traço aqui em cima e aqui embaixo, faço um outro centro com mesmo raio, traço aqui em cima e aqui embaixo. [...]"
\end{abstract}

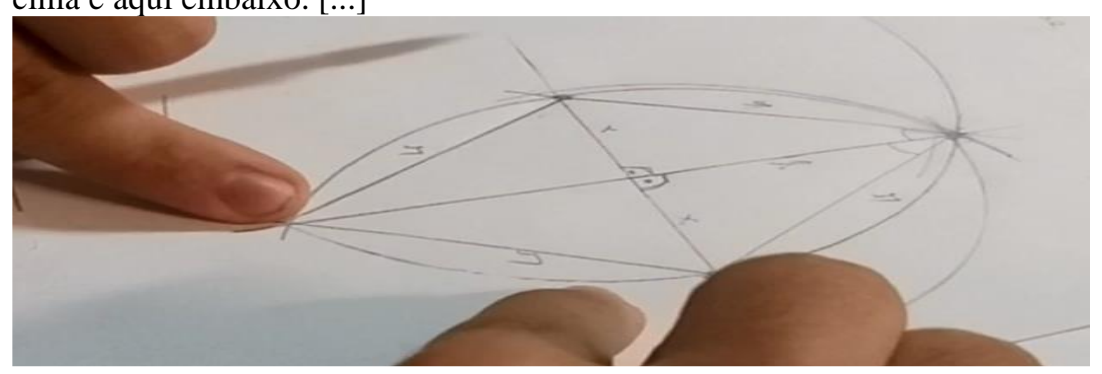

(OLIVEIRA, 2019, p. 99, grifo nosso).

A expressão "faço um outro centro" aponta uma imprecisão na Linguagem Matemática do aluno, pois não é possível fazer um outro centro, visto que cada circunferência possui apenas um centro. No contexto da explicação do estudante, seria, mais coerente ele dizer que "traço outra circunferência a partir do segundo ponto tomado inicialmente". Conforme Gawned (1990), o exercício de analisar o que se fala ajuda a moldar o pensamento, nesse sentido, é necessário sempre que possível, que docentes façam intervenções em incoerências de linguagem dessa natureza.

Em outro momento da atividade, na discussão das estratégias de uso do instrumento jacente no plano, os discentes voltam a apresentar algumas incoerências na linguagem. Como se pode observar na imagem seguinte (figura 4), uma delas se refere à construção de um plano:

Figura 4 - Escrita do Grupo 3 sobre a construção de um plano tomando como referência retas

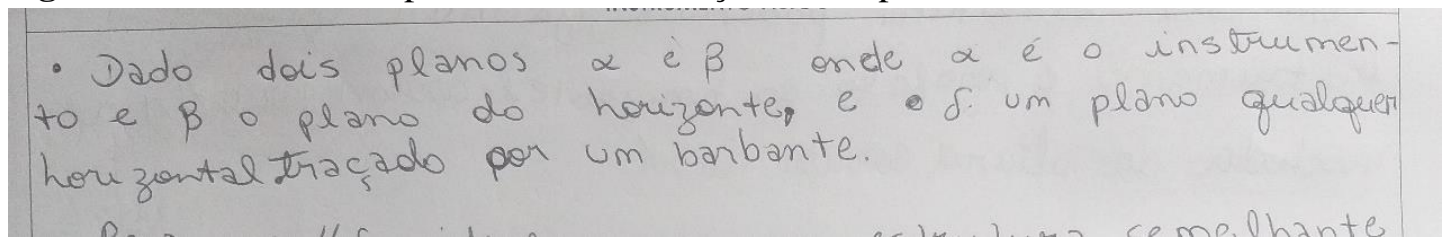

Fonte: Oliveira (2019)

Percebe-se que inicialmente os estudantes falam de dois planos, em que $\alpha$ representa a tábua do instrumento jacente e o plano $\beta$ seria o plano do horizonte, a 
imprecisão está no excerto que afirma " $\delta$ um plano qualquer horizontal traçado por um barbante". Considerando que o barbante esteja esticado, ele faz referência a um segmento de reta, mesmo assim, sabe-se que um plano não pode ser formado por uma única reta. Duas retas formam um plano, desde que tenham exatamente um ponto em comum, ou seja, sejam concorrentes entre si (LIMA, et al. 2016). Outra possibilidade para determinar um plano seria trabalhar com um conjunto de retas todas paralelas uma, a outra e ambas coplanares entre si.

Outra imprecisão, diz respeito ao uso da noção de posição relativa entre reta e plano. No relatório do grupo 1, nota-se o seguinte excerto (figura 5):

Figura 5 - Escrita do Grupo 1 que tem incorporado o significado de posição relativa entre reta e plano

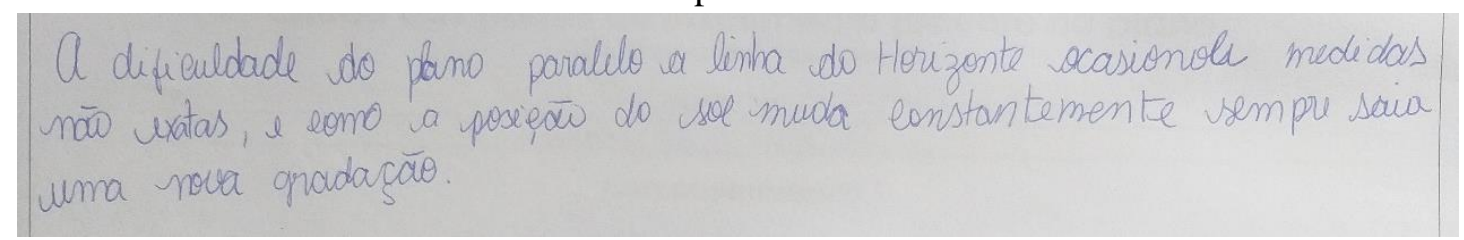

Fonte: Oliveira (2019)

Nesse excerto, chama atenção a parte em que se tem "a dificuldade do plano paralelo à linha do horizonte". Ao descrever o instrumento jacente no plano, Nunes (2008) fala de plano do horizonte e não de linha do horizonte. Nesse caso, verifica-se uma imprecisão na interpretação matemática do texto de Nunes (2008). Tratar como linha do horizonte, mobiliza na situação de uso a noção de posição relativa entre reta e plano, em que "uma reta pode não ter pontos em comum com um plano (dizemos que a reta e o plano são paralelos)" (LIMA, et al. 2016, p. 159).

Em alguns diálogos, é possível verificar ainda mais imprecisões na linguagem geométrica, por exemplo, ao tratarem sobre arco e corda de circunferência, tem-se a seguinte afirmação do aluno 4: "a corda é uma reta que intersecta a circunferência em até dois pontos, um ou dois pontos" (OLIVEIRA, 2019, p. 110, grifo nosso). Pelo que se sabe, uma corda não é uma reta, mas sim um segmento de reta (REZENDE; QUEIROZ, 2008). 


\section{Notas finais}

Diante do exposto, nota-se que há algumas imprecisões na Linguagem Geométrica de discentes da Licenciatura em Matemática da UECE. Diante desse fato, à luz do referencial teórico assumido, sabe-se que a precisão na linguagem é uma das ferramentas didáticas básicas requeridas de um docente. Nesse sentido, entende-se que a linguagem dos estudantes deve ser explorada pelos professores como elemento para favorecer a formação ampla e sólido do conhecimento do conteúdo necessário a prática profissional.

A linguagem adquire seu valor formativo, devido à possibilidade de proporcionar aos docentes uma ferramenta para fazer intervenções no movimento do pensamento de estudantes da Licenciatura em Matemática. Ao serem questionados sobre sua fala ou escrita, os estudantes passam a refletir, a moldar, a sistematizar e a refinar tanto as suas ideias, e seus argumentos como também seus conhecimentos.

Esse estudo, se insere em um conjunto de pesquisas que já têm apontado para a necessidade de considerar elementos e fatores da Linguagem Matemática em processos de formação. Como perspectiva para estudos futuros, tem-se como intenção analisar a precisão na linguagem de discentes em um conjunto maior de pesquisas, abrangendo em particular as que se desenvolveram sobre os moldes da proposta de construção de interface entre história e ensino de matemática apontada por Saito e Dias (2013) e Pereira e Saito (2019).

\section{Referências}

ALBUQUERQUE, Luís de. Instrumentos de Navegação. Lisboa: Comissão Nacional para a Comemoração dos Descobrimentos Portugueses, 1988.

\footnotetext{
ALMEIDA, Bruno José M. G. Pereira de. A influência da obra de Pedro Nunes na náutica dos séculos XVI e XVII: um estudo de transmissão de conhecimento.2011. 595 f. Tese (Doutorado) -Universidade de Lisboa Faculdade de Ciências Secção Autónoma de História e Filosofia das Ciências, Curso de Doutoramento em História e Filosofia das Ciências, Lisboa, 2011. Disponível em: <http://repositorio.ul.pt/handle/10451/6699 >. Acesso em: 12 jul. 2018.

CANAS, António José Duarte Costa. A obra náutica de João Baptista Lavanha (c. 1550 - 1624). 2011. 401 f. Tese (Doutorado) - Doutoramento em história especialidade - História dos Descobrimentos e Expansão, Universidade de Lisboa Faculdade de Letras Departamento de História, Lisboa, 2011. Disponível em: < http://repositorio.ul.pt/handle/10451/6140>. Acesso em: 08 nov. 2018.
} 
ELLERTON, Nerida F.; CLARKSON, PHILIP C. Language factors in Mathematics teaching and learning A. J. Bishop et al. (Eds.). International Handbook of Mathematics Education, 1996, pp. 987-1033.

GAWNED, S. 'An Emerging Model of the Language of Mathematics', in J. Bickmor e Brand (ed.), Language in Mathematics, Australian Reading Association, Carlton, Vic. 1990, p. 27-42.

GODOY, Arilda Schmidt. Pesquisa Qualitativa Tipos Fundamentais. Raje-revista de Administração de Empresas, São Paulo, v. 35, n. 3, p.20-29,1995. Disponível em: < http://www.scielo.br/pdf/rae/v35n3/a04v35n3.pdf>. Acesso em: 15 maio 2018.

LEITÃO, Henrique. Anotações ao De arte atque ratione nauigandi. In Pedro Nunes. Obras, vol. IV, Lisboa: Academia das Ciências de Lisboa, Fundação Calouste Gulbenkian, 2008, p. 515-794.

\section{LEITÃO, Henrique. Ars e Ratio: A Náutica e a Constituição da Ciência Moderna,} In: La ciência y el mar. Valladolid: Los autores, p. 183-207, 2006.

LEITÃO, Henrique. Para uma biografia de Pedro Nunes: o surgimento de um matemático, 1502-1542. Cadernos de Estudos Sefarditas, Lisboa, v. 3, p.45-82, 2003.

LIMA, Elon Lages. et al. A matemática do ensino médio - volume 2. Rio de Janeiro: Sociedade Brasileira de Matemática. 2016.

MACHADO, Nílson José. Matemática e Realidade: Das concepções às ações docentes. São Paulo: Cortez, 2013.

MARCONI, Marina de Andrade; LAKATOS, Eva Maria. Fundamentos de metodologia científica. 5. ed. São Paulo: Atlas, 2003.

MENEZES, Luís. Matemática, linguagem e comunicação. Millenium, 2000.

MORAIS FILHO, Daniel Cordeiro de. Manual de redação matemática: com um dicionário etimológico - Explicativo de palavras usadas na matemática e um capítulo especial sobre como se escreve um dissertação. Campina Grande, Fábrica de Ensino, 2010 .

MOURA, Manoel Oriosvaldo de. et al. A Atividade Orientadora de Ensino como Unidade entre Ensino e Aprendizagem. In: MOURA, Manoel Oriosvaldo de. (Org). A atividade pedagógica na teoria histórico-cultural. Campinas, São Paulo: Autores associados, 2016.

NUNES, Paulo Jorge Antunes. Os instrumentos náuticos na obra de Pedro Nunes. 2012. 162 f. Dissertação (Mestrado) - Curso de Mestrado de História Marítima, Universidade de Lisboa Faculdade de Letras Departamento de História, Lisboa, 2012. Disponível em: < http://repositorio.ul.pt/handle/10451/8968>. Acesso em: 12 jul. 2018. 
NUNES, Pedro. Obras: De Arte Atque Ratione Navigandi. vol. IV, Lisboa: Fundação Calouste Gulbenkian, 2008.

USISKIN, Zalman. Mathematics as a Language. In P. C. Elliott e M. J. Kenney (Eds.). Communication in Mathematics: 1996 Yearbook (pp. 231-243). Reston, VA: NCTM, 1996.

OLIVEIRA, Francisco Wagner Soares; PEREIRA, Ana Carolina Costa. Elementos iniciais da relação entre o instrumento de Pedro Nunes, jacente no plano, e o cálculo da latitude no século XVI. História da Ciência e Ensino: Construindo interfaces, São Paulo, v. 19, p. 39-53, 2019. Disponível em:

$<$ https://revistas.pucsp.br/hcensino/article/view/42112/29300 >. Acesso em: 14 set. 2019.

OLIVEIRA, Francisco Wagner Soares. Sobre os conhecimentos geométricos incorporados na construção e no uso do instrumento jacente no plano de Pedro Nunes (1502-1578) na formação do professor de matemática. 2019. $199 \mathrm{f}$. Dissertação (Mestrado) - Curso de Mestrado em Ensino de Ciências e Matemática, Instituto Federal de Educação, Ciência e Tecnologia do Ceará, Fortaleza, 2019.

PEREIRA, Ana Carolina Costa; SAITO, Fumikazu. A reconstrução do báculo de Petrus Ramus na interface entre história e ensino de matemática. Cocar, Belém-PA, V. 13, n 25, p. 342-372, 2019.

REIS, António Estácio do. Os instrumentos de medida. As Novidades do Mundo: conhecimento e representação na Época Moderna, Lisboa, Edições Colibri, 2003, pp. 145-167.

REZENDE, Eliana Quelho Frota; QUEIROZ, Maria Lúcia Bontorim de. GEOMETRIA EUCLIDIANA PLANA e construções geométricas. São Paulo: Unicamp, 2008.

SAITO, Fumikazu.; DIAS, Marisa da Silva. Interface entre história da matemática e ensino: uma atividade desenvolvida com base num documento do século XVI. Ciências \& Educação (Bauru), São Paulo, v. 19, n. 1, p. 89-111, 2013. 